ISBN 978-93-84468-86-6

2016 International Research Conference on Practices in Law Business and Education

(PLBE-16)

Pattaya (Thailand) Dec. 16-17, 2016

\title{
General Weighted Average, Mental Ability and Battery Test Scores of Teacher Education Students
}

\author{
*Alberto J. Valenzuela, Marilyn S. De Leon, Editha N. De Regla and Edwin A. Estrella \\ *Bulacan State University, City of Malolos, Bulacan, Philippines
}

\begin{abstract}
The researchers used a cross-sectional descriptive study design. This study attempted to establish the perceived association among the general weighted averages, mental ability test scores, battery test scores of freshman teacher education students.

The researchers relied heavily on questionnaire as the major instruments in gathering information from the respondents. In order to gauge the mental ability of the respondents, the MD5 Mental Ability Test which is a quick and easy test of mental ability which involves finding missing letters, numbers or words was used. Furthermore, the faculty of instruction of the College of Education of the Bulacan State University Bustos Campus A.Y. 2015-2016 came up with a 100-item questionnaire that consists of questions ranging from general education subjects to professional subjects and this was utilized as the battery test. The general weighted average scores were collated from the Certificate of Grades that was issued by the university registrar to each bona fide teacher education student in the university.

It was established in this study that the battery test scores and the mental ability test scores of the respondents are positively correlated ( $p$ value $=0.0191$ ). This means that if the scores in the battery test go high, the scores in the mental ability test will also go high, or vise-versa. On the other hand, the general weighted averages of the respondents and their scores in the battery test are negatively correlated ( $p$ value $=<0.0001$ ). This means that if the scores in the general weighted average go up, the scores in the battery test will go down, or vise-versa.

It is also revealed in this study that about $40.35 \%$ of the variation in general weighted average may be explained by battery test scores and mental ability scores. Ten point increase in the battery test score leads to a 0.37 decrease in the general weighted average while holding the mental ability test score constant.

The researchers recommend that further studies ought to be pursued using the same model but a different set of respondents. The researchers feel that increasing the sample size will increase the statistical efficiency of the study. A non-parametric correlation may also be conducted considering the size of the presently sampled population.
\end{abstract}

Keywords: general weighted average, mental ability, battery test and college students

\section{Introduction}

The consistent decline in the quality of education in the Philippines can be attributed to a confluence of factors that beseeched the nation over the years. Once considered as one of the prominent pacesetters in South East Asia, the erstwhile leader has been relegated to the tail end of the pack. Many congressional studies in the past have all blamed the slow economic growth, inadequate government revenues, poverty and rapid population growth as the major culprits in this vicissitude. Slaydoven (2008) states that corruption and flawed management exacerbate the problem and these factors contribute to poor quality of teacher training, shortage of teachers, overcrowded and under-equipped classrooms, increasing drop-out rates and insufficient access to education for the poor.

The poor performance of basic education graduates in national administered examinations is nothing short of dismal and unremarkable. As Roces (2006) puts it, quality assurance lost face and started its slow descent during the Marcos era. Widespread graft and corruption took its toll heavily on the nation's economy. He furthers that because of the failing economy and lack of job opportunities then, majority of highly-educated workforce, including teachers, were left with no choice but to search for greener pastures away from the 
academe, and what's even worse is, found their feet in the shores of other countries. Regretfully, some teachers just settled for meager jobs that are way below their college training and qualifications, yet higher paying that the roles they left in the classrooms. (But of course, this mismatch is totally another story and deserves another research study).

To make matters even worse, the teacher education course nowadays does not profess much lure among high school graduates. The cream of the crop of each graduating batch from the basic education of the modern times are often attracted and enticed by the sheen and glamour of the courses in engineering, architecture, commerce, medical fields, information technology and the likes. Surely, these courses show lots of promise and other professions are more lucrative on the other side of the fence.

Personal interviews among freshman college students taking up the teacher education course would reveal that their decision to pursue a degree in education is not really theirs, but their parents', guardians' or benefactors'. Given the choice, (and chance), they admit that they would rather be in other courses except education. Financial restraints and failure in admission examinations from other colleges are usually what prompted these individuals to enroll in the course that is least of their priority. Others say that a career in education seems a good fallback from their failed dreams or careers in other fields.

Meanwhile, students' academic gain and learning performance, as discussed by Shoukat et al. (2013), is affected by numerous factor including gender, age, teaching faculty, students schooling, father/guardian social economic status, residential area of students, medium of instructions in schools, tuition trend, daily study hour and the like. Many researchers conducted detailed studies about the factors contributing student performance at different study levels. Furthermore, student's academic performance, according to Mendezabal (2013) occupies a very important place in education as well as the learning process. She posits that it is considered as a key criterion to judge one's total potentialities and capacities which are frequently measured by the examination results. It is used to pass judgments on the quality of education offered by academic institution.

Hence, the College of Education of the Bulacan State University Bustos Campus has heightened its efforts to boost the ante in screening the teacher aspirants. In its pursuit to raise the bar of excellence among its graduates, it has decided to administer a battery examination among its students. Those who will fail in the said examination will be advised to take another course. Furthermore, in order to lift the academic standards of the institution more than the ordinary, a mental ability test has also been given to the same students.

Teachers are the primary nation-builders (Ramos, 2008). They are the ultimate source of empowerment. They guide the nation to the ladder of opportunities. That is why, it is quite imperative to improve the competencies of teacher education graduates because they are not just a tribute to the university, but also to the country. These researchers believe that a teacher aspirant's performance is based on an interplay of so many cognitive and noncognitive factors. There are many existing studies that attempt to identify that significant predictors and outcomes of a teacher's job performance. However, there seems to be no accurate angle that can clearly and absolutely explain that road to a successful career in the academe. In this study, the researchers attempted to investigate the possible association among the general weighted average, mental ability scores, and battery examination scores of freshmen teacher education students.

\section{Statement of the Problem}

The general problem of this study was: Is there a significant association that exists among the general weighted averages, mental ability test scores and battery test scores of freshmen teacher education students at the Bulacan State University Bustos Campus A.Y. 2015-2016?

Specifically, this study sought answers to the following questions:

1. What are the general weighted averages of the respondents?

2. What are the levels of mental ability of the respondents?

3. What are the battery test scores of the respondents?

4. What is the extent of the association that exists among the variables?

\section{Significance of the Study}

The College of Education of the Bulacan State University Bustos Campus has heightened its desire to produce quality graduates that will not only be able to meet the national standards, but also be able to measure up to their foreign counterparts. In its pursuit to raise the bar of excellence among its graduates, it has decided to 
administer a battery examination among its students. Those who will fail in the said examination will be advised to take another course. Furthermore, in order to lift the academic standards of the institution more than the ordinary, a mental ability test has also been given to the same students.

Hence this study is deemed significant to school administrators, psychologists and curriculum planners as this will give them an idea of the kind of association that exists among the general weighted average, mental ability and battery examination scores of freshmen teacher education students. The results of this study will guide them on the retro-fitting adjustments that need to be implemented in order to produce quality teachers. A clear and established association among the variables will serve as a significant predictor on the quality of graduates as resonated from the program of the institution. Specifically, this study will reveal if the mental ability and scores in the battery examination administered to the students have a significant effect on their academic performance.

This study may also serve for benchmarking purposes, source of inspiration, documentation, pattern and catharsis to other researchers and writers out there who are in a quandary of pursuing a similar study. The writers strongly suggest to budding researchers to pursue a correlational study with a different angle or twists, involving the same or dissimilar variables, or even pair them with other variables such as gender, age, motivation, religion, socio-economic status, and the like.

\section{Conceptual Framework}

The significant association that exists among the general weighted average, mental ability and battery examination scores of freshman teacher education students at the Bulacan State University Bustos Campus A.Y. 2015-2016 can be conceptualized by using the paradigm shown in Figure 1.

\section{Independent Variables Dependent Variable}

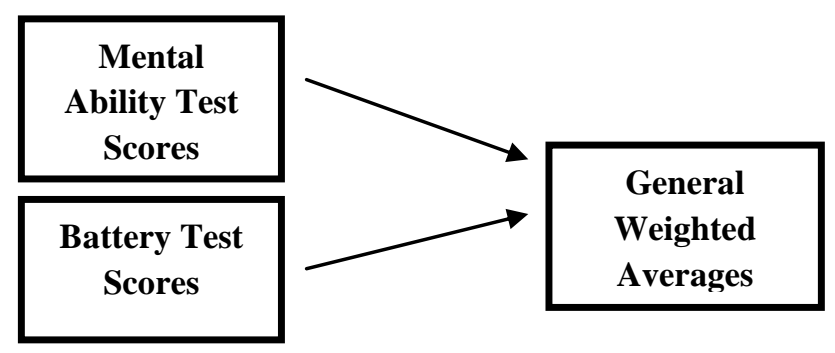

Fig. 1 Conceptual Framework of the Study

Frame 1 and 2 of the graphic representation shows the independent variables in the study which are the mental ability test scores and battery test scores of freshman teacher education students at the Bulacan State University Bustos Campus A.Y. 2015-2016.

Frame 3 of the graphic representation shows the dependent variable in the study which is the general weighted averages of freshman teacher education students at the Bulacan State University Bustos Campus A.Y. 2015-2016.

\section{Methods and Techniques of the Study}

The researcher used the cross-sectional descriptive study design. This study attempted to establish the perceived association among the general weighted average, mental ability and battery examination scores of freshman teacher education students at the Bulacan State University Bustos Campus A.Y. 2015-2016. According to Best, as cited by Calderon and Gonzales (1993), a descriptive study describes and interprets a manifestation of perceived relationship or association. It is concerned with conditions of relationships that exist, practices that prevail.

To be able to establish the association among the aforementioned variables, the researcher requested from the Guidance Office of the institution the scores of the mental ability of the respondents. Permission was sought from the Area Chair of the College of Education to allow the researcher access to the scores from the battery test of the respondents, together with their general weighted average. The results were analyzed by a statistician to see the association among the variables. 


\section{Research Instruments}

The researchers relied heavily on questionnaire as the major instruments in gathering information from the respondents. In order to gauge the mental ability of the respondents, this study requested from the Guidance Office the results of the MD5 Mental Ability Test which is a quick and easy test of mental ability which involves finding missing letters, numbers or words. This test, according to the PTS Insight, is designed to assess a person's ability to use logic and reasoning to solve cryptic problems, under a tight time pressure. The MD5 test also looks at the ability to deduce relationships and to apply the rules governing them, which are commonly considered to be fundamental components of "intelligence".

Furthermore, the faculty of instruction of the College of Education of the Bulacan State University Bustos Campus A.Y. 2015-2016 came up with a 100-item questionnaire that consists of questions ranging from general education subjects to professional education. The general weighted average scores were collated from the Certificate of Grades that was issued by the university registrar to each bona fide teacher education student.

\section{Data Gathering Procedure}

To be able to establish the association among the aforementioned variables, the researchers personally requested from the Guidance Office of the institution the scores of the mental ability of the respondents. Permission was sought from the Area Chair of the College of Education to allow the researchers access to the scores from the battery test of the respondents, together with their general weighted average as reflected in the Certificates of Grades that were issued by the university registrar.

\section{Data Processing and Statistical Treatment}

Data analysis was limited to the use of the following statistical tools: frequency count percentage, weighted mean and standard deviation to find the descriptive measures of the independent and dependent variables in this study. The data was further subjected to linear regression analysis in order to establish the correlation and thus measure the association among the general weighted average, mental ability and battery test scores of freshman teacher education students at the Bulacan State University Bustos Campus A.Y. 2015-2016.

\section{Results and Discussion}

The population of this study included fifty freshman students enrolled at the College of Education of the Bulacan State University Bustos Campus A.Y. 2015-2016. Table 1 shows the population of the study.

TABLE I Population of the Study

\begin{tabular}{|c|c|c|}
\hline Gender & Frequency & \% \\
\hline Male & 13 & 26 \\
\hline Female & 37 & 74 \\
\hline Total & $\mathrm{n}=50$ & 100 \\
\hline
\end{tabular}

It can be gleaned from the table that the entire universe or total enumeration of the population in one section was used as respondents in this study. There were thirteen males and thirty-seven females who were in section I$\mathrm{J}$ during the second semester of the specified academic year. This only confirms the fact that there are more females than males who pursue a career in teaching (Dela Pena, 2011).

Table 2 shows the distribution of respondents according to the general weighted average.

TABLE II Distribution of Respondents According to General Weighted Average

\begin{tabular}{|c|c|c|c|}
\hline Limit & Description & Frequency & \% \\
\hline $1.0-1.51$ & Outstanding & 25 & 50 \\
\hline $2.0-1.50$ & Very Satisfactory & 18 & 14 \\
\hline $3.0-2.01$ & Satisfactory & 7 & - \\
\hline $4.0-3.01$ & Needs Improvement & - & - \\
\hline $5.0-4.01$ & Poor & - & 100 \\
\hline & & Total 50 & \\
\hline
\end{tabular}


It can be gleaned from the table that half of the respondents or fifty percent were outstanding in their academic performance. Thirty-six percent of the respondents performed very satisfactorily and the performance of the remaining fourteen percent was pegged at a satisfactory level. None of the respondents performed below the satisfactory level.

Table 3 shows the distribution of respondents according to mental ability.

TABLE III Distribution of Respondents According to Mental Ability

\begin{tabular}{|c|c|c|}
\hline Remark & Frequency & \% \\
\hline Superior & - & - \\
\hline Above Average & 2 & 4 \\
\hline Average & 23 & 46 \\
\hline Below Average & 22 & 44 \\
\hline Poor & 3 & 6 \\
\hline & Total 50 & 100 \\
\hline
\end{tabular}

It can be gleaned from the table that four percent of the respondents have an Above Average mental ability, forty-six percent are Average, and forty-four percent are Below Average. Unfortunately, the table shows that six percent of the respondents have a poor mental ability.

Table 4 shows the distribution according to battery examination scores.

TABLE IV Distribution of Respondents According to Battery Test Scores

\begin{tabular}{|c|c|c|c|}
\hline Limit & Description & Frequency & \% \\
\hline $100-90$ & Excellent & - & 22 \\
\hline $89-85$ & Very Good & 11 & 38 \\
\hline $84-80$ & Good & 19 & 30 \\
\hline $79-75$ & Fair & 15 & 10 \\
\hline $74-$-below & Failed & 5 & 100 \\
\hline
\end{tabular}

It can be gleaned from the table that twenty-two percent of the respondents performed "Very Good" in the Battery Examination, thirty-eight percent performed at a level characterized as "Good", and thirty percent performed at a level characterized as "Fair". Unfortunately, ten percent of the respondents failed in the battery examination administered by the institution.

Figure 2 depicts the histograms of the general weighted averages, mental ability test scores and battery test scores of the respondents respectively.
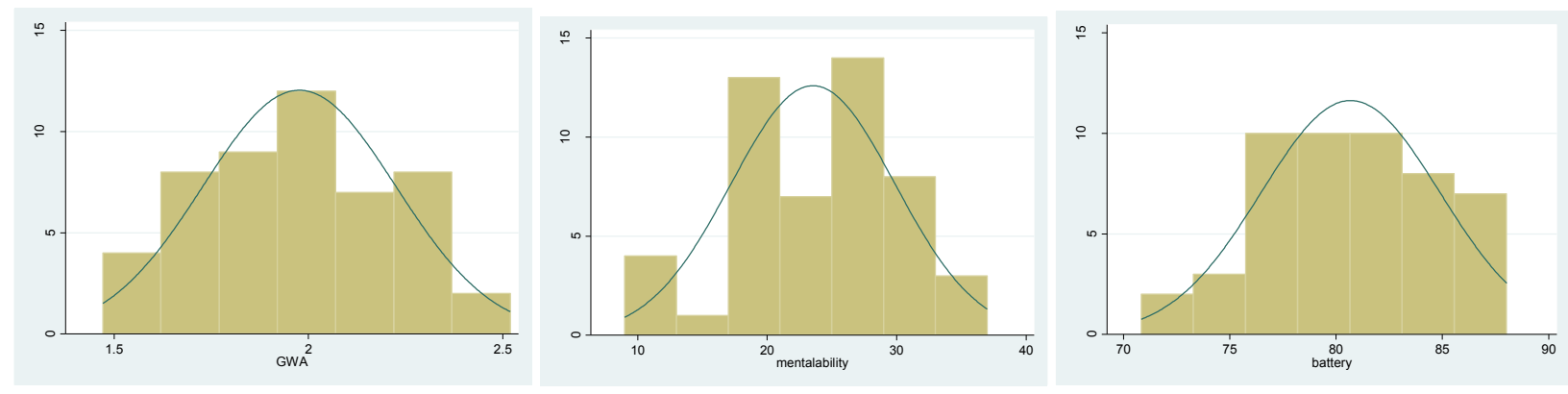

Fig. 2 Histograms of the Variables in this Study

The figure depicts the distribution of the respondents illustrated in histograms for general weighted averages, mental ability test scores and battery examination scores of the respondents respectively. Table 5 shows the descriptive statistics that gives a thorough analysis of the data in this study. 
TABLE V Descriptive Statistics of the Variables in the Study

stats |mental ability battery test GWA

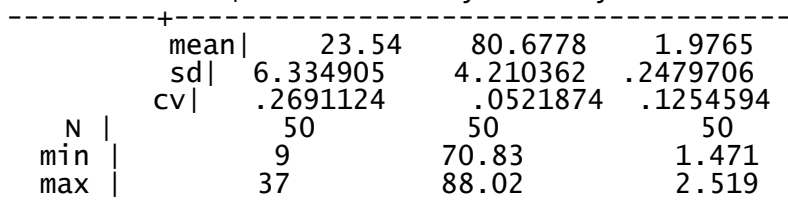

where: mean $=$ mean, $\mathrm{sd}=$ standard deviation, $\mathrm{cv}=$ coefficient of variation, $\mathrm{N}=$ sample size, min $=$ minimum value, $\max =$ maximum value

It can be gleaned from the table that the mean score in the mental ability test of the respondents is 23.54 with a standard deviation of 6.33 and a coefficient of variation at .27. The mean score in the battery test is 80.68 with a standard deviation of 4.21 and a coefficient of variation at .05 . The mean score in the general weighted averages is 1.98 with a standard deviation of .25 and a coefficient of variation at .13 .

Figure 3 shows the scatter plots of the variables in the study.

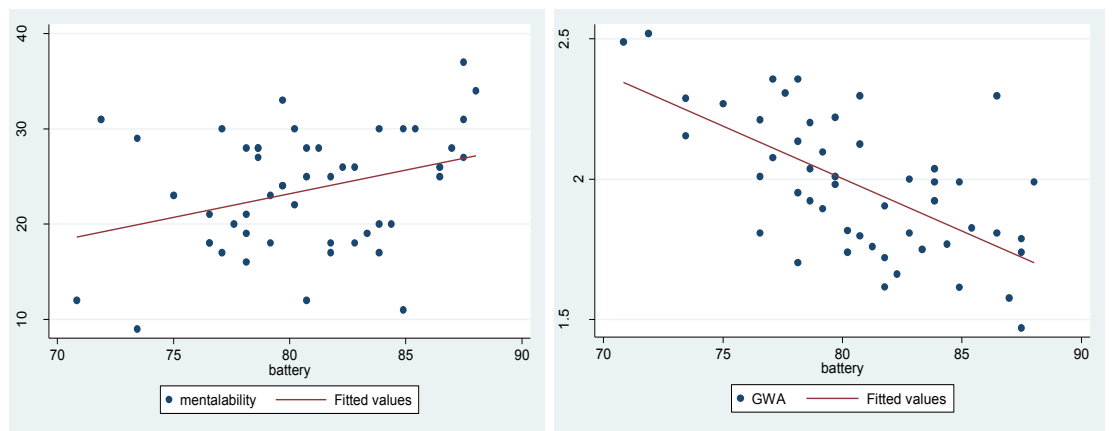

Fig. 3 Scatter Plots of the Variables in the Study

The first graph in the figure shows the scatter plot of mental ability test score and battery test scores of the respondents in this study with the line of best fit. This shows that there exists a positive linear relationship between the two variables.

On the other hand, the second graph in the figure shows the scatter plot of the general weighted averages and the battery test scores of the respondents in this study with the line of best fit. This shows that there exists a negative linear relationship between the two variables.

Table 6 shows the pairwise correlation of the variables in the study.

TABLE VI Pairwise Correlation of the Variables in the Study

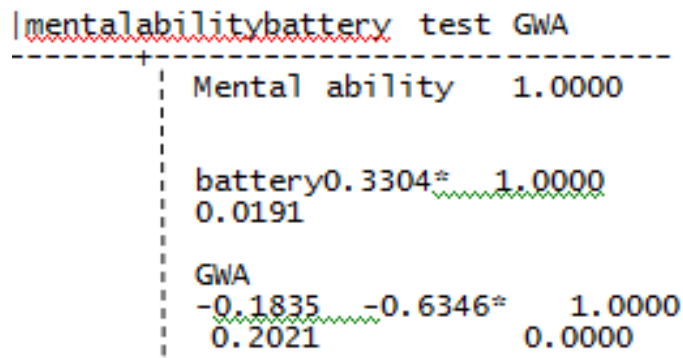

It can be gleaned from the table that the battery test scores and the mental ability test scores of the respondents are positively correlated $(\mathrm{p}$ value $=0.0191)$. This means that if the scores in the battery test go high, the scores in the mental ability test will also go high, or vise-versa. On the other hand, the general weighted averages of the respondents and their scores in the battery test are negatively correlated ( $\mathrm{p}$ value $=<0.0001$ ). This means that if the scores in the general weighted average go up, the scores in the battery test will go down, or vise-versa. This means further that if the academic performance of the teacher education student is remarkable, his score in the battery test will not be as such.

However, Bux (2014) explained in her paper entitled, "The Relationship between the Cognitive Test and the Academic Performance of Students in an MBA Program", she mentions that a theoretical relationship was established between the variables in her study. The empirical relationship revealed statistically significant 
relationships between the cognitive tests and the academic performance of the students which is contrary or opposite of what was established in the result of this study.

On the other hand, the study of Dzulkifli and Alias (2012) entitled "Students of Low Academic Achievement -Their Personality, Mental Abilities and Academic Performance: How Counsellor Can Help?", they posit that the correlational analysis and independent Sample T-test revealed that personality traits of the low and high achieving students are the same except for assertiveness. In addition there exist significant relationships between personality traits and cognitive abilities only in low achievers.

Interestingly enough, the table shows that no significant correlation was established between the mental ability and the academic performance of the respondents in this study.

Table 7 shows the multiple regression of the variables in this study.

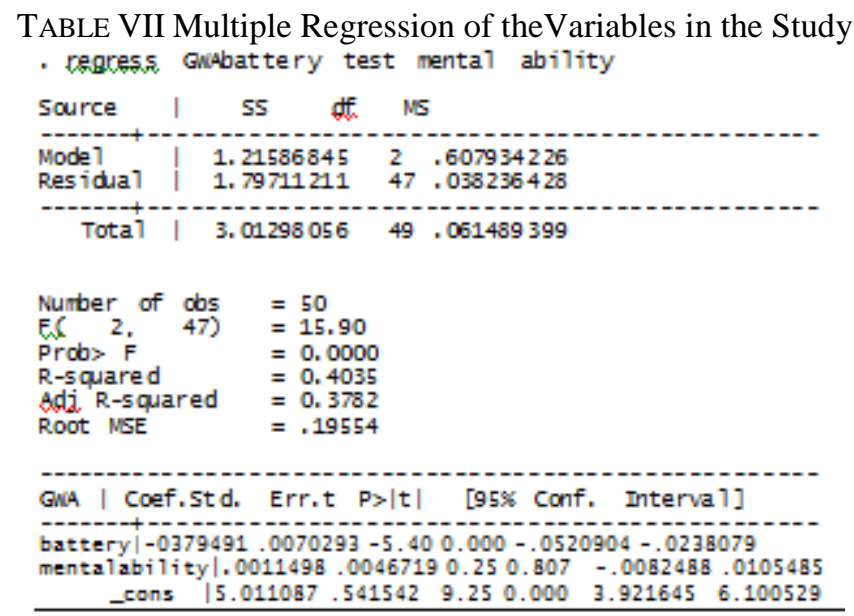

Multiple Linear Regression reveals that about $40.35 \%$ of the variation in the general weighted average may be explained by the battery test scores and mental ability scores. The linear regression model is significant as indicated by the p-value of the F-statistic with 2 and 47 degrees of freedom equal to $<0.0001$. A ten point increase in the battery test score leads to a 0.37 decrease in the general weighted average while holding the mental ability scores constant. This is suggested by the p-value of the corresponding t-statistic that is equal to $<0.001$ and at the $95 \%$ confidence interval $(-0.052,-0.024)$. However, the mental ability scores are not a significant predictor of general weighted average as manifested by a p-value of 0.807 .

\section{Conclusion}

On the basis of the significant findings of this study, the following conclusions are drawn:

1. Majority of the respondents have an "outstanding" academic performance.

2. Majority of the respondents have an "average" mental ability.

3. Majority of the respondents faired "good" in the battery test.

4. The battery test scores and the mental ability test scores of the respondents are positively correlated.

5. The general weighted averages of the respondents and their scores in the battery test are negatively correlated.

6. Ten point increase in the BTS leads to a 0.37 decrease in the GWA while holding the MAT scores constant.

\section{Recommendations}

1. Further studies can be pursued using the same model but a different set of respondents.

2. The researchers strongly feel that increasing the sample size will increase the statistical efficiency of the study.

3. A non-parametric correlation may also be pursued considering the size of the presently sampled population. 


\section{Bibliography}

[1] Bux, Ciara (2014). The Relationship between the Cognitive Test and the Academic Performance of Students in an MBA Program, Retrieved on April 15, 2016, Available at http://uir.unisa.ac.za/bitstream/handle/10500/18826/dissertation_bux_c.pdf?sequence=1

[2] Dzulkifli, Mariam Adawiah and IntanAidura Alias (2012).Students of Low AcademicAchievement-Their Personality, Mental Abilities and Academic Performance: How Counsellor Can Help?", Retrieved on April 15, 2016, Available at http://www.ijhssnet.com/journals/Vol_2_No_23_December_2012/25.pdf

[3] Mendezabal, M. J. N. (2013). Study Habits and Attitudes: The Road to Academic Success, Open Science Repository, English Language Medium, (Accessed on August 16, 2014). e70081928. doi:10.7392/Education.70081928

[4] Roces, Alejandro R (2006). The Decline in Quality of Philippine Education.Retrieved on April on April 28, 2016, Available at http://www.philstar.com/opinion/369945/decline-quality-philippine-education

[5] Shoukat, A., Haider Z., Munir, F., Khan, H., \& Ahmed, A. (2013).Factors Contributing to the Students' Academic Performance: A Case Study of Islamic University Sub-Campus, American Journal of Education Research. (Accessed on August 16, 2014). Available at http://pubs.sciepub.com/education/1/8/3/

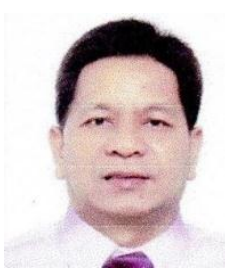

\section{Dr. Alberto J. Valenzuela}

He finished his Doctor of Education, Major in Educational Management at Bulacan State University, City of Malolos, Bulacan, Philippines. He is currently the Dean of BulSU-Bustos Campus. Prior to his assignment as Dean, he was a member of the BulSU's Board of Regents while serving his term as President of the Faculty Union. He is also the author of a research entitled; Recruitment and Selection Process of Faculty in the Higher Education Institutions in the Philippines which was published in the International Conference Proceedings on Arts, Education and Interdisciplinary Studios (AEIS-16) at

Dubai UAE in 2016.

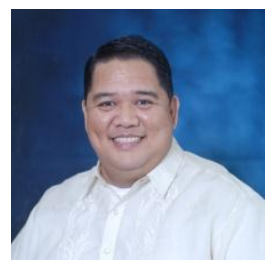

\section{Dr. Edwin A. Estrella}

Professor 1 at the Bulacan State University and handles English and professional education subjects at the College of Education and also functions as a Student Teaching supervisor. He is also a faculty researcher of the university.

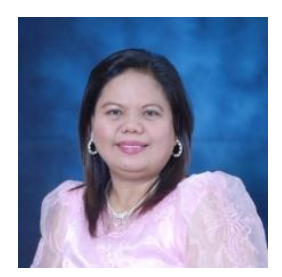

\section{Ms. Edith N. De Regla}

Associate Professor at Bulacan State University and handles science subjects at the College of Education. She also serves as a curriculum coordinator in the same college. Presently, she is a faculty researcher in the campus.

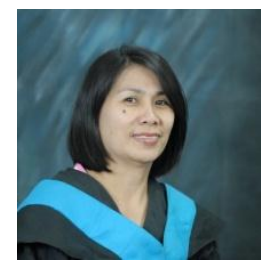

\section{Ms. Marilyn S. De Leon}

Associate Professor at Bulacan State University and handles Food Technology subjects at the College of Industrial Technology. She had been Area Chair of the College of Industrial Technology and currently, she is a faculty researcher in the said college. 